\title{
Too Cold for a Jog? Weather, Exercise, and Socioeconomic Status
}

\section{Daniel Eisenberg and Edward Okeke}

Department of Health Management and Policy

University of Michigan, School of Public Health

(daneis@umich.edu, blkwrt@umich.edu)

\begin{abstract}
Socioeconomic gradients in health behaviors such as exercise are extensively documented but the reasons behind these gradients are poorly understood. This study examines a potentially important factor in socioeconomic gradients in one particular context, by estimating how exercise responds to a plausibly exogenous "price shock," in the form of weather conditions. Most notably, we find that within cold temperature ranges, a decrease in past-month temperature causes a significant decrease in past-month exercise, and this effect is generally larger for lower education and income groups. In large part this differential by socioeconomic group appears to be due to smaller increases in indoor activity during cold weather. These results suggest that interventions and policies aiming to increase exercise participation, particularly among lower socioeconomic populations, could do so in part by increasing the availability and attractiveness of indoor facilities and activities. Furthermore, to the extent that the higher elasticity of behavior for lower socioeconomic groups reflects a more general sensitivity to external factors, this highlights the promise of interventions that address such factors more broadly.
\end{abstract}




\section{Introduction}

The socioeconomic gradient in health behaviors is well-documented but poorly understood. For example, less educated people are more likely to drink heavily and smoke, and less likely to exercise and eat fruits and vegetables regularly, but the mechanisms behind such differentials are difficult to disentangle (Cutler and Lleras-Muney, 2006). While researchers have posited a wide range of explanations related to discount rates, information, cognitive ability, preferences for health versus other commodities, and social networks, determining the independent causal effects of any of these factors is subject to considerable problems with measurement and selection bias.

This study focuses on socioeconomic differences in how exercise behavior, often referred to in the public health literature as leisure time physical activity (LTPA), responds to weather shocks. Because weather is well-measured and plausibly exogenous, it offers an opportunity to obtain definitive causal estimates related to differences in health behaviors by socioeconomic status. Improving understanding of the determinants of LTPA is valuable for at least three reasons. First, numerous studies show strong negative correlations between exercise and the risk of developing heart disease (Berlin and Colditz, 1990) and many other health conditions such as colon cancer (e.g. Gerhardsson et al, 1990). Second, despite these apparent health benefits, fewer than half of American adults engage in regular LTPA (CDC 2007), and this behavior exhibits a large gradient by socioeconomic status (SES), as defined by education or income (He and Baker (2005). This differential in exercise behavior by SES has been posited as a major contributor to the large disparities by SES in obesity and cardiovascular health (Mensah et al, 2005).

Third, the determinants of exercise behavior are not well understood, as they are difficult to disentangle in empirical research - why do some people exercise while others do not, and what prompts people to start or stop exercising regularly? Many of the commonly hypothesized factors - e.g., health-related knowledge and beliefs, proximity to other people who exercise, proximity to exercise facilities or activities, and local climate - are likely to be correlated with unmeasured factors that affect LTPA, such as preferences related to LTPA. Thus, while we can easily observe correlations between these factors and LTPA, we do not know to what extent these factors actually cause LTPA. If the objective is to increase LTPA, an improved understanding of causal factors is an important step towards designing more effective interventions and policies.

Our methodological approach is to estimate how weather that is abnormal for a given location and time of year, as measured by temperature and precipitation, affects the likelihood, intensity, and type (indoor versus outdoor) of 
LTPA. We then examine how this response varies by SES, as measured by income and education.

To preview our results, we find that temperature has a modest, statistically significant effect on LTPA and this effect is generally larger for people with lower educational attainment or lower income. Within cold temperature ranges (which we define as less than 60 degrees Fahrenheit), a five degree decrease in past-month average daily maximum temperature causes a 2.5 percent decrease (relative to the mean) in the probability of meeting CDC guidelines for exercise in the past month, and this effect is 2-3 times larger for some lower education and income groups as compared to the higher SES groups. We also find evidence that suggests substitution between indoor and outdoor activities. Within colder temperature ranges, a decrease in temperature causes a decrease in outdoor activities and an increase in indoor activities. The degree of shifting towards indoor activities during cold weather, however, appears to be lower among lower SES groups, suggesting that differential access to indoor activities may explain a large part of the differential overall response of LTPA to weather shocks.

These results can help inform the design of the large and growing number of interventions to increase physical activity. Given that activity is sensitive to weather conditions and this sensitivity varies by SES, interventions to address LTPA in general and SES differentials in particular may need to be tailored accordingly (e.g. by increasing the availability of indoor activities). From a broader perspective, this analysis tells us something basic about the determinants of health behaviors - in this case, temporary shocks such as current weather conditions matter, and they seem to matter especially for lower income and education groups. The fact that exercise behavior can be manipulated by temporary shocks highlights the opportunity to affect behavior via interventions; furthermore, these temporary shocks may have longer-term implications, given that exercise is believed to be a habit-forming activity (Aarts et al, 1997).

\section{Related Literature and Hypotheses}

Cawley (2004) offers a starting point for thinking about how people make decisions about exercise. In his "SLOTH" framework, people allocate their time to the following activities: sleep (S), leisure (including physical activity) (L), occupation (O), transportation $(\mathrm{T})$, and home production $(\mathrm{H})$. In a utilitymaximizing allocation of time, the marginal utility of the last hour spent in each activity must be the same for all activities. In this framework, one can think of weather as changing the marginal utility of hours spent in outdoor LTPA. For example, an unusually cold day during the winter would decrease the marginal utility of outdoor LTPA. This would cause a decline in outdoor activity and 
substitution towards other activities. To the extent that indoor and outdoor LTPA are close substitutes, indoor LTPA would increase.

Humphreys \& Ruseski (2006, 2007) extend the SLOTH framework on three dimensions: 1) they distinguish between the participation and duration decisions (extensive and intensive margins) for LTPA; 2) they distinguish between types of physical activity (e.g., outdoor versus indoor, and group versus individual); 3) they acknowledge that LTPA often requires not only time but also purchased goods and services. Given this last factor, they show theoretically that income can have a positive effect on the participation decision (e.g., due to the need to buy goods and services associated with the activities) but a negative effect on the duration decision (due to the opportunity cost of time), and they find empirical support for this hypothesis.

Extending their logic, one can see that people with higher income may be less affected by weather shocks, in terms of total LTPA (indoor plus outdoor), if they purchase more goods and services that facilitate indoor LTPA. For example, given that higher income people are more likely to hold a gym membership (Powell et al, 2006; Hillsdon et al, 2007), then the marginal cost of substituting to indoor activities during foul weather may be lower. This may also be true for more educated people, independent of income. For example, if more educated people on average have a lower discount rate or tend to plan future activities more carefully, then they may be more likely to make purchases (such as a gym membership) that will serve as "insurance" against the disutility of not having desirable alternatives for exercise (in terms of benefits and costs) during foul weather. Also, gym memberships may serve as commitment devices (costs paid upfront) for people who are aware of the time-inconsistency in their preferences related to LTPA; part of the calculus for these people may be that they know that weather shocks will deter them from exercising unless they have a low marginal cost alternative in place.

Another layer of complexity comes from the fact that many people engage in physical activity in their jobs. As Philipson and Posner (1999) describe, this may have significant implications for LTPA, overall physical activity, and body weight. It is not clear a priori, however, how having a job with significant physical activity would affect the response of LTPA to weather shocks. If, for example, unusually bad weather means that one is not as physically active as usual on the job (e.g., rain prevents one from working on an outdoor project), then one might actually increase LTPA in order to maintain a preferred level of overall activity. On the other hand, if occupational activity and LTPA are not considered close substitutes, then this may not occur.

Whether one is employed or unemployed at a given point in time may also affect the response of LTPA to weather. Ruhm (2000) finds that exercise is positively correlated with the unemployment rate, and Ruhm (2005) finds that 
exercise increases particularly among previously inactive people during periods of high unemployment. If unemployed people have more flexibility in their schedule, they may be able to mitigate the impact of weather shocks on their LTPA (e.g., by waiting for poor weather to pass, and by taking advantage of unusually good weather when it arrives). On the other hand, the LTPA of unemployed people may be more affected by inclement weather to the extent that the factors related to lower income and lower education (discussed above) apply to them.

Based on the concepts and literature described above, we begin our empirical analysis with three general hypotheses. First, overall LTPA falls during periods of unusually "bad" (very hot, very cold, or wet) weather, due to the reduced marginal utility of outdoor LTPA. Second, the reduction in outdoor LTPA is at least partially offset by increased indoor LTPA. Third, the overall response of LTPA is inversely related to SES, due to a lesser degree of substitution from outdoor to indoor activity.

\section{Methods}

\section{Empirical Framework}

Some studies have demonstrated significant seasonal variation in LTPA, with activity typically peaking in warmer seasons (Pivarnik et al, 2003; Matthews 2001). These correlations, however, would not necessarily identify causal effects of weather. Seasonal variations in LTPA may be due to factors other than weather, such as changes in time allocation related to holiday, school, or work schedules. Also, across-area correlations between climate and LTPA may be due to the fact that people who enjoy exercise locate in areas with milder or drier weather, rather than a true causal relationship. In order to address such confounding factors, we adopt an approach focusing on weather variations that cannot be anticipated. To do this, we include state-by-month fixed effects (a fixed effect for each state-month combination) in our regressions. This approach, in effect, controls for the fact that each state has "typical" weather conditions during each month of the year and people are well aware of these patterns (and they may adjust their habits and even where they decide to live accordingly). The analysis thus focuses on the deviations from the typical patterns, estimating whether unusual temperatures or precipitation for a given state-month combination are associated with a deviation from "normal" exercise behavior in that state-month. 
Specifically, we estimate linear regressions (and logistic regressions in sensitivity checks for binary dependent variables) with a full set of state-by-month fixed effects and year fixed effects, as summarized in the following equation:

$$
\begin{aligned}
& \text { LTPA }_{\text {isymd }}=\beta_{0}+\beta_{1} \text { tmax } 30_{\text {symd }}+\beta_{2} \text { precip } 30_{\text {symd }}+\beta_{3} X_{i}+\gamma_{1} \text { statemonth }_{\text {sm }} \\
& +\gamma_{2} \text { year }_{y}+\varepsilon_{\text {isymd }}
\end{aligned}
$$

Subscripts denote, respectively, person $i$, state $s$, year $y$, month $m$, and day (calendar date) $d$. LTPA represents a measure of exercise (as detailed in the next section describing the data), tmax30 is the average daily maximum temperature (in Fahrenheit) in the state in the 30 days priors to the date of the BRFSS interview, precip30 is the average daily precipitation (in $\mathrm{cm}$ ) in the state during the prior 30 days, $X$ is a set of demographic variables (age categories and gender), statemonth is a full set of dummies interacting state and month (48*12 $=576$ dummies), and year is a full set of year dummies (1993-2000).

We specify a functional form allowing for a nonlinear relationship between LTPA and temperature. In particular, we hypothesize that the relationship is positive in lower temperature ranges and negative in higher temperature ranges. In other words, very cold and very hot temperatures are less conducive to exercise, as compared to moderate temperatures. To allow for this possibility, we estimate the regression described above with linear splines in the relationship between tmax30 and LTPA. This allows for different slopes over different intervals of tmax30. We chose three intervals: tmax30<60, $60<=$ tmax30<= 80, and tmax30 > 80, based on a simple plot of LTPA and tmax30 (Figure 1), which roughly shows a steeper slope below 60 degrees, a flatter but still positive slope between 60 and 80 , and a flat slope above 80 (t-tests comparing the slopes of these splines confirm that they are different at $\mathrm{p}<0.01$ in each pairwise comparison). By contrast, because we hypothesize that precipitation has a monotonically negative relationship with the net benefit of exercise, we specify precipitation as a linear term.

We then estimate all regressions by SES group, defined by either education or income group, in order to evaluate whether certain types of people are more sensitive to adverse weather. All regressions include Taylor series linearized standard errors clustered by state. 
Figure 1: Exercise (\% meeting CDC guidelines) by Average Daily Maximum Temperature $(F)$ in past 30 days

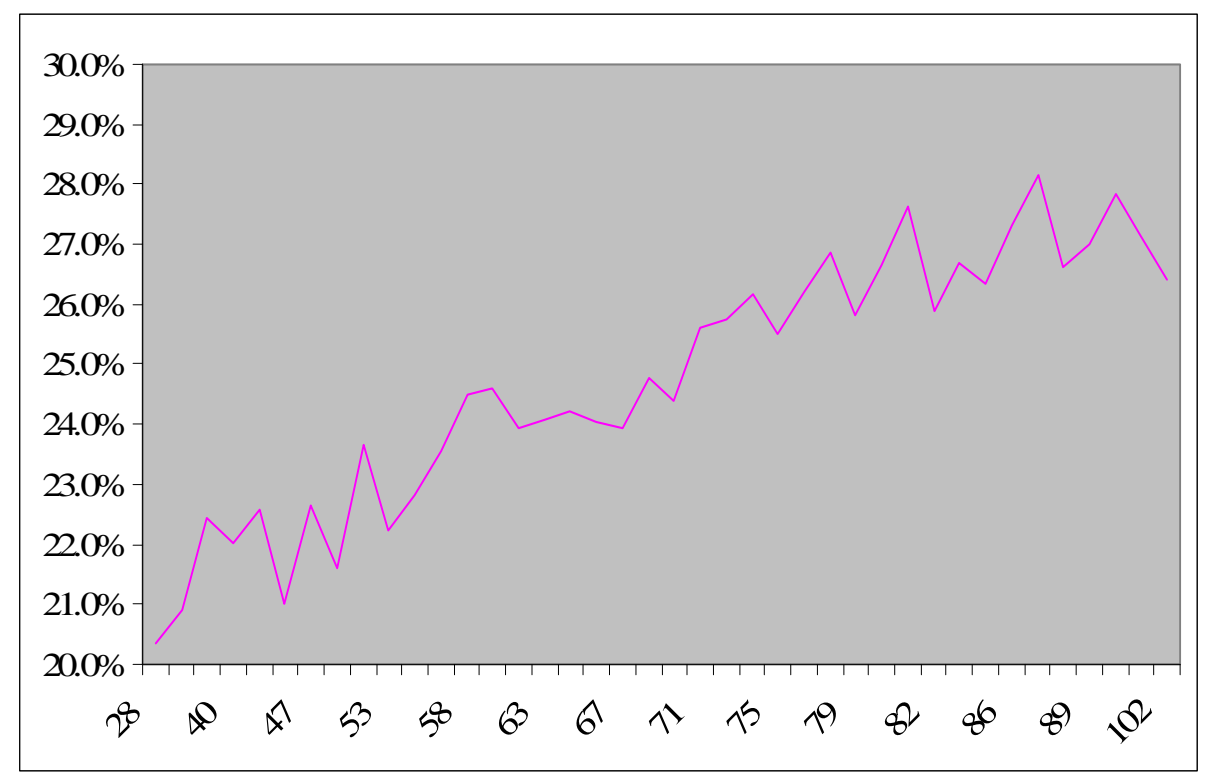

Data points represent \% of people in BRFSS (1993-2000) meeting CDC guidelines for regular exercise in each of 40 quantiles defined by average daily maximum temperature (Fahrenheit) in the past 30 days.

\section{Data and Variables}

We link two publicly available data sets: individual level data from the Behavioral Risk Factor Surveillance System (BRFSS) and weather data from the National Climatic Data Center (NCDC). BRFSS is an annual, cross-sectional, telephonebased survey of adults 18 and older that asks about health-related behaviors, and is representative at both state and national levels. Our sample includes the 48 contiguous states and years 1993-2000. Questions about leisure time physical activity (LTPA) were asked in all 48 states during the even years, and in a subset of states (ranging in number from 10 to 12 depending on the year) that opted to include them during the odd years. Our total sample with information about LTPA consists of 522,939 people. We do not include more recent years because in 2001 the BRFSS stopped asking about types of LTPA, which are important for our analysis of outdoor versus indoor activities. We link the individual-level BRFSS data to state-level weather data using the exact BRFSS interview date and state identifiers.

Regarding LTPA, BRFSS asked respondents a series of questions, as follows. All respondents were first asked, "During the past month, did you 
participate in any physical activities or exercises such as running, calisthenics, golf, gardening, or walking for exercise?” If the answer was yes, respondents were then asked, "What type of physical activity or exercise did you spend the most time doing during the past month?" The respondents could then select from a list of 56 activities (see Appendix A) including items such as "jogging," "basketball," and "health club exercise." The respondents were then asked two follow-up questions for the selected activity: "How many times per week or per month did you take part in this activity during the past month?" and "And when you took part in this activity, for how many minutes or hours did you usually keep at it?”

For those who reported an exercise activity, BRFSS then queried about a second activity: "Was there another physical activity or exercise that you participated in during the last month?” If the answer was yes, respondents were asked, "What other type of physical activity gave you the next most exercise during the past month?” followed by the questions above regarding frequency and duration.

In our main analyses, we examine three different measures of LTPA: 1) whether the individual met recent CDC guidelines for LTPA; 2) whether the individual reported any LTPA (the extensive margin); 3) the number of hours per week of LTPA, among those who reported any positive amount (the intensive margin).

The CDC guidelines recommend that adults engage in "moderate-intensity physical activities for at least 30 minutes on 5 or more days of the week" or "vigorous-intensity physical activity on 3 or more days per week for 20 or more minutes per occasion" (CDC 2006). The guidelines include specifics about which activities are considered "moderate-intensity" and "vigorous-intensity." In order to construct an indicator variable for meeting these guidelines, we first code each activity in the BRFSS data as "moderate-intensity" or "vigorous-intensity" based on the guide provided by the CDC. This guide defines activities with metabolic equivalents of 3-6 as moderate and more than 6 as vigorous (see http://prevention.sph.sc.edu/tools/docs/documents_compendium.pdf). Because the CDC guidelines do not explicitly state how one might meet them through some combination of moderate and vigorous activities, we make the assumption that one session of moderate activity (of 30 or more minutes) is equivalent to three-fifths of a session of vigorous activity (of 20 or more minutes). We chose the 3/5 ratio based on the fact that the CDC recommends either three instances of vigorous activity or five of moderate. We then coded a person as meeting the CDC guidelines if he or she completed the equivalent of 3 sessions of vigorous activity per week. So, for example, a person could accomplish this through 2 weekly sessions of vigorous activity and 2 of moderate activity. 
In some specifications we classify LTPA according to whether the activity is outdoor or indoor. For some activities such as fishing, mowing the lawn, and health club exercise, the outdoor/indoor classification is clear, whereas for other activities the classification is not clear (e.g., jogging, which could easily be outdoor or indoor on a treadmill). Therefore we classify activities according to whether they were "clearly outdoor," "mostly outdoor," "clearly indoor," or "mostly indoor." Because we are not aware of definitive data to guide these classifications, we use our own judgments. Appendix A shows our classifications, as well as other information about each activity that BRFSS respondents could list. In our primary analysis of the outdoor/indoor dichotomy, we use broader definitions of outdoor and indoor, which include both the "clearly" and the "mostly" categories. As a specification check, we re-run the analyses, restricting the definitions of outdoor and indoor activities to the more clear-cut cases.

Weather data are taken from the National Climatic Data Center's (NCDC) Cooperative Summary of the Day, TD 3200, a database containing historical daily weather measures from over 20,000 weather stations in the U.S. To match the past-month time frame of the exercise variables, we construct weather variables that summarize conditions over the 30 days preceding each respondent's interview date within that person's state of residence. For temperature, we reason that daily maximum temperatures are more relevant for physical activity than daily minimum temperatures (and daily time-weighted average temperatures are not available in the databases we use), because the maximum would better approximate the conditions during most people's waking hours. Therefore, we calculate the average daily maximum temperature over the past 30 days within the state. Similarly, we calculate the average daily precipitation (in centimeters) over the past 30 days within the state.

We aggregate individual weather station data into state-level weather measures in two steps. First, we aggregate individual weather station measures up to division level averages (in U.S. weather databases, each state is divided into up to 9 geographic divisions). Second, we calculate a weighted average of divisionlevel measures within each state-day, where the weights are equal to the land areas of the divisions. Ideally we would weight weather station data by surrounding population mass, but this was not feasible given available data. To address the fact that our state-level weather measures are probably less accurately matched to individual persons in states with more land area, we conduct sensitivity analyses using only the 24 continental states below the median in land area.

We measure SES in two ways: by educational attainment and by income. Defining SES by educational attainment, we group people into three categories: less than or equal to a high school degree or equivalent, some college but no 
college degree, and greater than or equal to a college degree or higher. Defining SES by household income, we group people into four categories: less than $\$ 15,000, \$ 15,000-\$ 25,000, \$ 25,000-\$ 50,000$, and more than $\$ 50,000$. These categories were chosen based on the limited number of response categories in the BRFSS data.

We include several control variables in the analysis. Demographic variables include age (divided into 6 categorical dummies: 18-24, 25-34, 35-44, 45-54, 55-64, 65 and older), gender, marital status (married or not), and race/ethnicity (white, non-Hispanic; black, non-Hispanic; white Hispanic; black Hispanic; other Hispanic; Asian or Pacific Islander; American Indian or Alaska Native; other non-Hispanic). In addition, we measure employment status based on whether the respondent reports being currently employed. We also include a measure of location type (metro, urban, or rural). In sensitivity checks, we conduct the analysis without these covariates. Given that these variables should not be correlated with weather shocks, we would not expect the results to be sensitive to their inclusion or exclusion (although we use them in our main analysis with the aim of improving the efficiency of our estimates).

\section{Results}

\section{Descriptive Statistics}

Table 1 shows mean values for all variables used in the analysis. Twenty four percent of people met CDC recommendations for exercise, and $70.8 \%$ reported any exercise activity in the past 30 days. Those reporting any exercise averaged 4.36 hours per week (SD $=5.4$ hours). Sixty percent of people engaged in outdoor exercise (defined as "mostly" or "clearly" outdoor, as shown in Appendix A) in the past 30 days, whereas indoor exercise (similarly defined) was less common(22.2\%). 


\section{Table 1: Means of key variables}

Mean SD

Dependent variables:

Met CDC recommendations for exercise, past 30 days $\quad 24.0 \%$

$\begin{array}{ll}\text { Any exercise, past } 30 \text { days } & 70.8 \%\end{array}$

Hours of exercise (among those with any), past 30 days $4.36 \mathrm{hrs}$

5.4 hrs

Outdoor exercise, past 30 days

$60.0 \%$

Indoor exercise, past 30 days

$22.2 \%$

Independent variables:

Temperature (average Fahrenheit daily max past 30 days)

$66.1 \mathrm{~F}$

$18.1 \mathrm{~F}$

Precipitation (average cm past 30 days)

$0.3 \mathrm{~cm} \quad 0.2 \mathrm{~cm}$

Age

46.8 yrs

17.6 yrs

Female

$59.0 \%$

Married

$55.0 \%$

Employed

$62.6 \%$

White Non-Hispanic

$83.5 \%$

Black Non-Hispanic

$7.4 \%$

White Hispanic

$4.0 \%$

Black Hispanic

$0.3 \%$

Other Hispanic

$1.9 \%$

Asian/Pacific Islander

$1.3 \%$

American Indian/Alaska Native

$1.1 \%$

Other Non-Hispanic

$0.6 \%$

$<\$ 15,000$ household income

$16.5 \%$

$\$ 15,000$ - \$25,000

$21.5 \%$

$\$ 25,000$ - \$50,000

$36.8 \%$

$>\$ 50,000$

$25.2 \%$

HS degree or less

$46.1 \%$

Some college

$27.8 \%$

College degree

$26.1 \%$

Data: BRFSS $(N=522,939)$ and National Climatic Data Center (1993-2000) 
Fifty nine percent of the sample was female, 55\% were married, and $62.6 \%$ were employed. The three most common race/ethnicity categories were white nonHispanic (83.5\%), black non-Hispanic (7.4\%), and white Hispanic (4.0\%). Finally, we note that the BRFSS interview dates for our sample were relatively evenly divided across months of the calendar year: each month accounted for between seven and nine percent of the sample.

For descriptive purposes, we show the seasonal variation in LTPA in Figures 2a-2d. Figure 2a includes the overall sample (all 48 continental states), and Figures 2b-2d divide the five most populous states into three groups: colder states in Figure 2b (Illinois and New York), warmer states in 2c (Florida and Texas), and a mild temperature state in $2 d$ (California). In the overall sample (Figure 2a), the probability of meeting CDC guidelines for LTPA follows a clear seasonal pattern, with the highest values (up to 28\%) during the summer months (June-August) and the lowest (down to 20\%) during winter months (DecemberFebruary). This is driven by fluctuations in outdoor activities, which follow the same pattern. Indoor activity, by contrast, is relatively flat across the year, at 21$22 \%$, except for a small tick upwards to $24 \%$ during January-March. In the warmer states (Figure 2b), outdoor activities are relatively flat across the year (with slight peaks in the spring and fall), and indoor activities peak in the hot summer months rather than the winter. By contrast, in the colder states (Figure 2c), outdoor activities are much more prevalent in the summer than in the winter, and indoor activities increase slightly in the winter. In California (Figure 2d), outdoor activities are somewhat more prevalent in the summer months, and indoor activities increase slightly in the summer and fall.

LTPA is negatively associated with SES (Table 2), which is consistent with studies noted earlier. For example, $19 \%$ of people with a high school degree or less met CDC guidelines for LTPA, as compared to $32 \%$ of people with a college degree. These patterns are similar across income categories. The differentials by SES categories in meeting CDC guidelines and exercising at all are all significant at $\mathrm{p}<0.01$. On the other hand, among people who exercised at all, the number of hours per week shows little variation across SES groups. This indicates that the disparities in exercise by SES are along the extensive, rather than intensive, margin. 
Figure 2a: Exercise by Month of Year, Full Sample (48 Continental States)

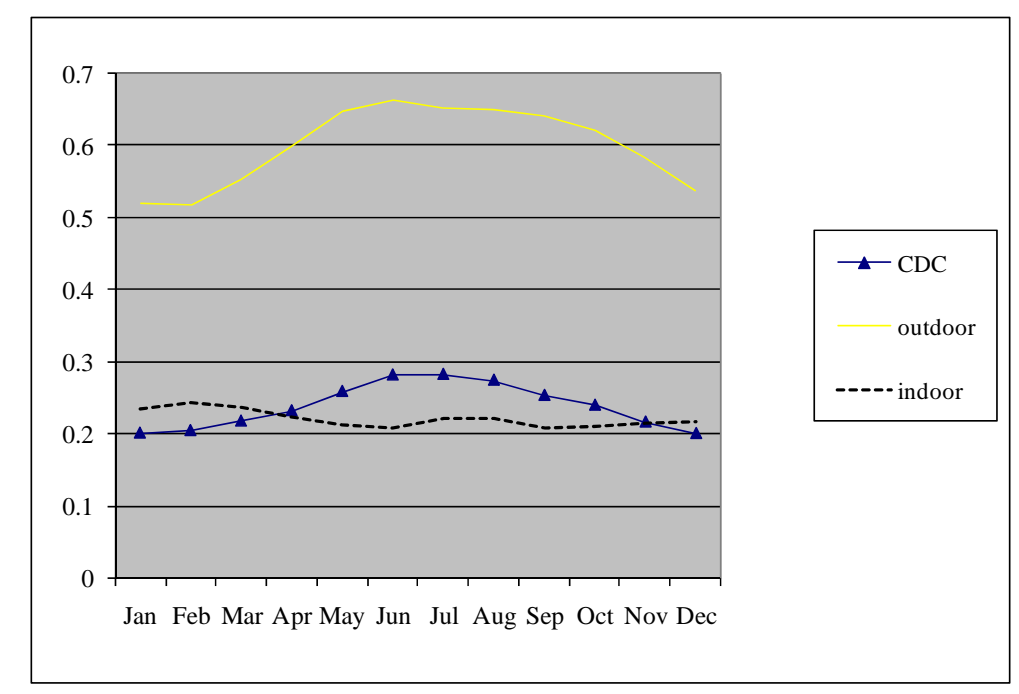

$C D C=\%$ meeting $C D C$ guidelines for regular exercise in past 30 days outdoor $=\%$ engaging in any outdoor exercise in past 30 days indoor $=\%$ engaging in any indoor exercise in past 30 days

Figure 2b: Exercise by Month of Year, Warmer States (Florida and Texas)

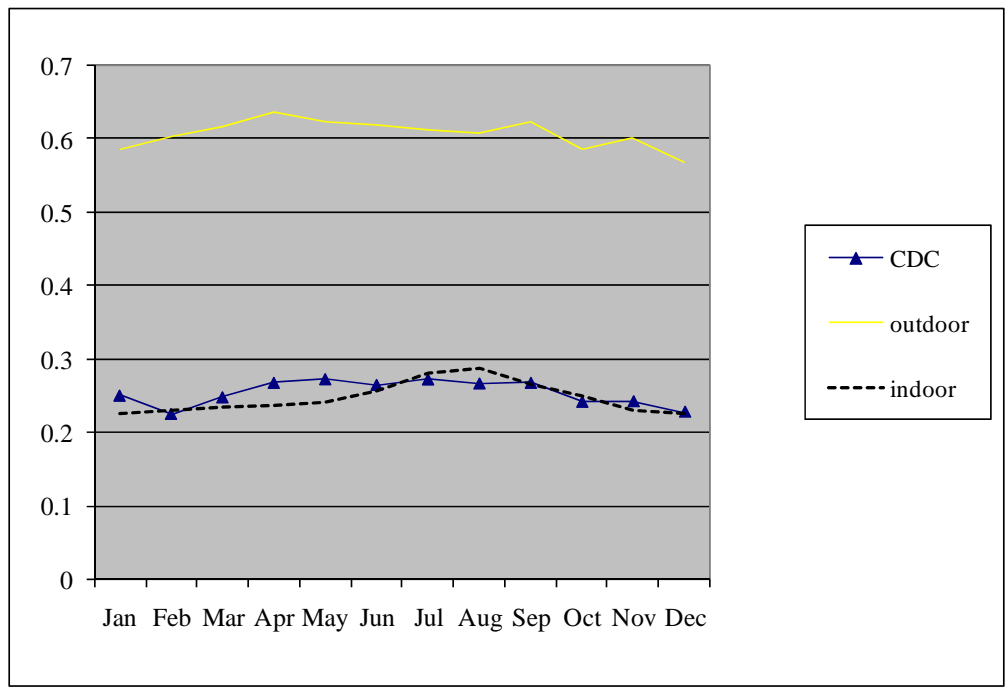

See notes to Figure 2a for variable definitions. 
Figure 2c: Exercise by Month of Year, Colder States (New York and Illinois)

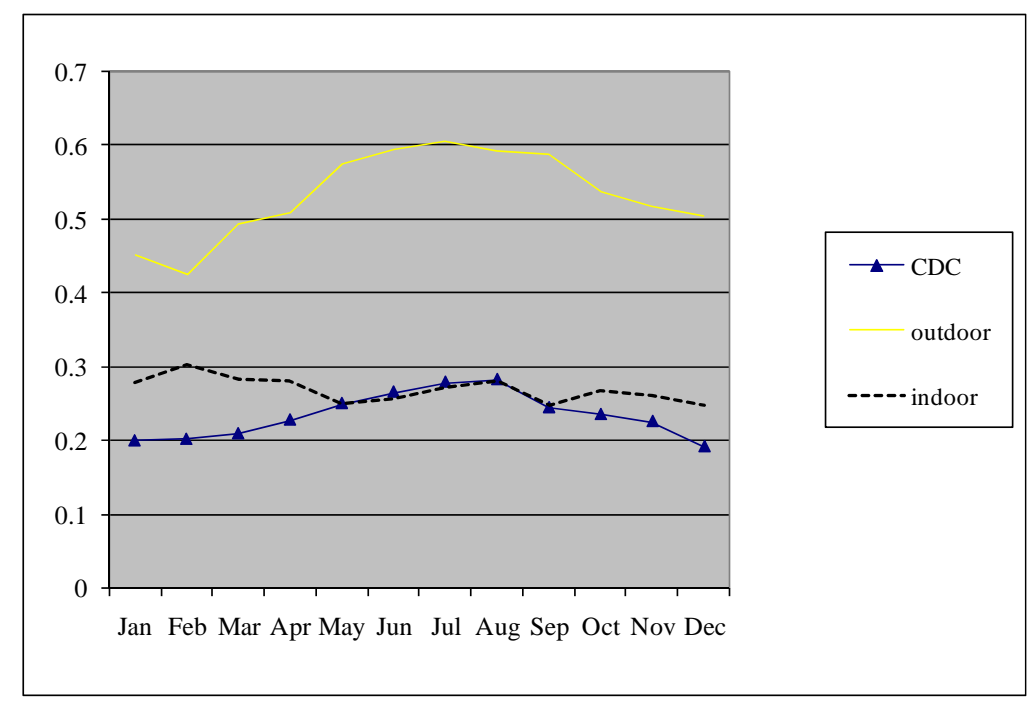

See notes to Figure 2 a for variable definitions.

Figure 2d: Exercise by Month of Year, Mild State (California)

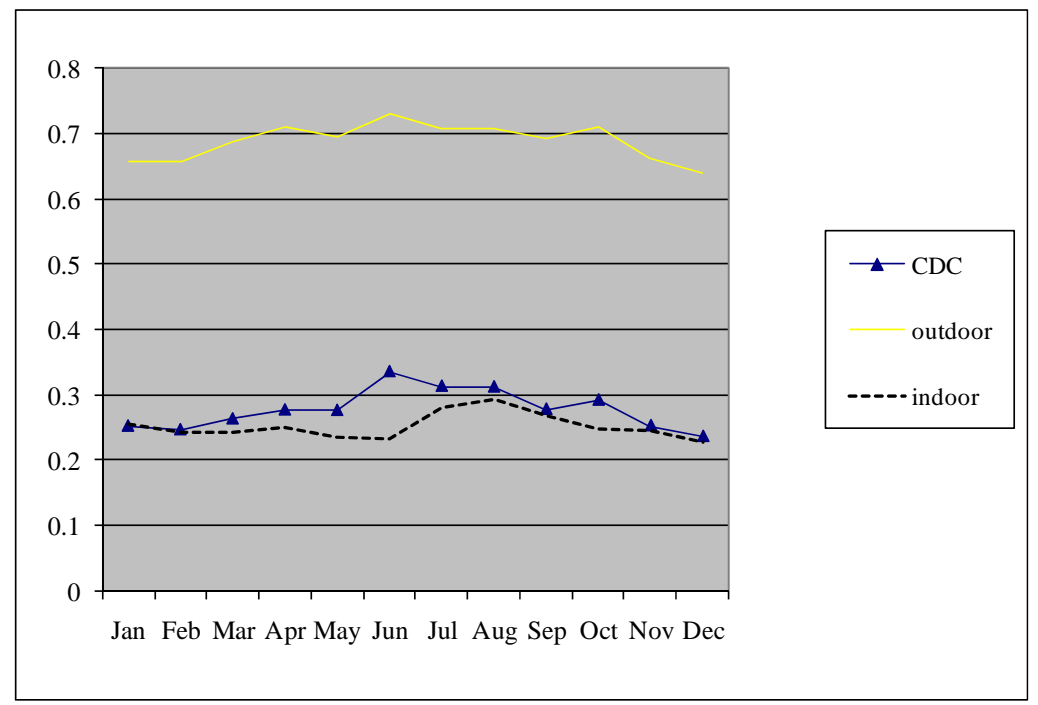

See notes to Figure 2 a for variable definitions. 
Table 2: Exercise, by Education and by Income

$\begin{array}{lccc} & \begin{array}{c}\text { Exercise } \\ \text { (met CDC } \\ \text { guidelines, past } \\ 30 \text { days) }\end{array} & \begin{array}{c}\text { Any } \\ \text { exercise } \\ \text { (past } 30 \\ \text { days) }\end{array} & \begin{array}{c}\text { Hrs per wk exercise, } \\ \text { given any (past 30 } \\ \text { days) }\end{array} \\ \text { HS degree or less } & 19 \% & 61 \% & 4.38 \\ \text { Some college } & 25 \% & 76 \% & 4.38 \\ \text { College degree } & 32 \% & 83 \% & 4.33 \\ & & & \\ <15,000 \text { income } & 19 \% & 58 \% & 4.34 \\ \$ 15,000 \text { - \$25,000 } & 21 \% & 66 \% & 4.35 \\ \$ 25,000-\$ 50,000 & 25 \% & 74 \% & 4.35 \\ >\$ 50,000 & 31 \% & 83 \% & 4.44\end{array}$

Data: BRFSS 1993-2000, $N=522,939$

Notes: differences in means across education and income categories are significant at $p<0.01$ for the first two measures of exercise (met CDC guidelines, and any exercise), whereas the differences in hours per week are significant only for college versus others $(p=0.03)$ and $>\$ 50,000$ versus others $(p<0.01)$.

\section{Effects of Weather on Exercise}

Table 3 shows our main results for the overall sample. The most robust relationship appears to be that between temperature within the low range $(<60$ degrees) and LTPA. This relationship is significantly positive at $\mathrm{p}<0.01$ for each measure of LTPA. Consistent with our hypothesis, this indicates that LTPA decreases as the temperature drops within cold temperature ranges (or that LTPA increases as the temperature rises). The magnitude of these estimates is modest, implying that, for example, a 5 degree drop in temperature causes the following: a 0.6 percentage point decline in meeting CDC guidelines (or 2.5 percent relative to the mean), a 1.1 percentage point decline in any exercise participation (3 percent relative to the mean), and a 0.06 decline in hours per week among those who exercise (1.4 percent relative to the mean). To place in context a 5 degree reduction in within-state-month temperature, consider that $84 \%$ of state-month combinations have at least one value (over the 8 years of data) that is 5 or more degrees below the state-month mean, and the average standard deviation in temperature within state-month is 3.8 degrees. Thus, a 5 degree reduction in temperature might be considered substantial but not exceptionally rare. 
In the middle and high temperature ranges, exercise is not significantly associated with temperature at $\mathrm{p}<0.05$. Also, precipitation is significantly associated $(\mathrm{p}<0.05)$ with meeting CDC guidelines for LTPA but not with the other two measures of LTPA. The magnitude of the significant estimate for precipitation is small, implying that people are 0.3 percentage points less likely to meet CDC guidelines during months with precipitation per day reduced by one standard deviation $(0.2 \mathrm{~cm})$.

\section{Table 3: Effect of Weather on Exercise, Full Sample}

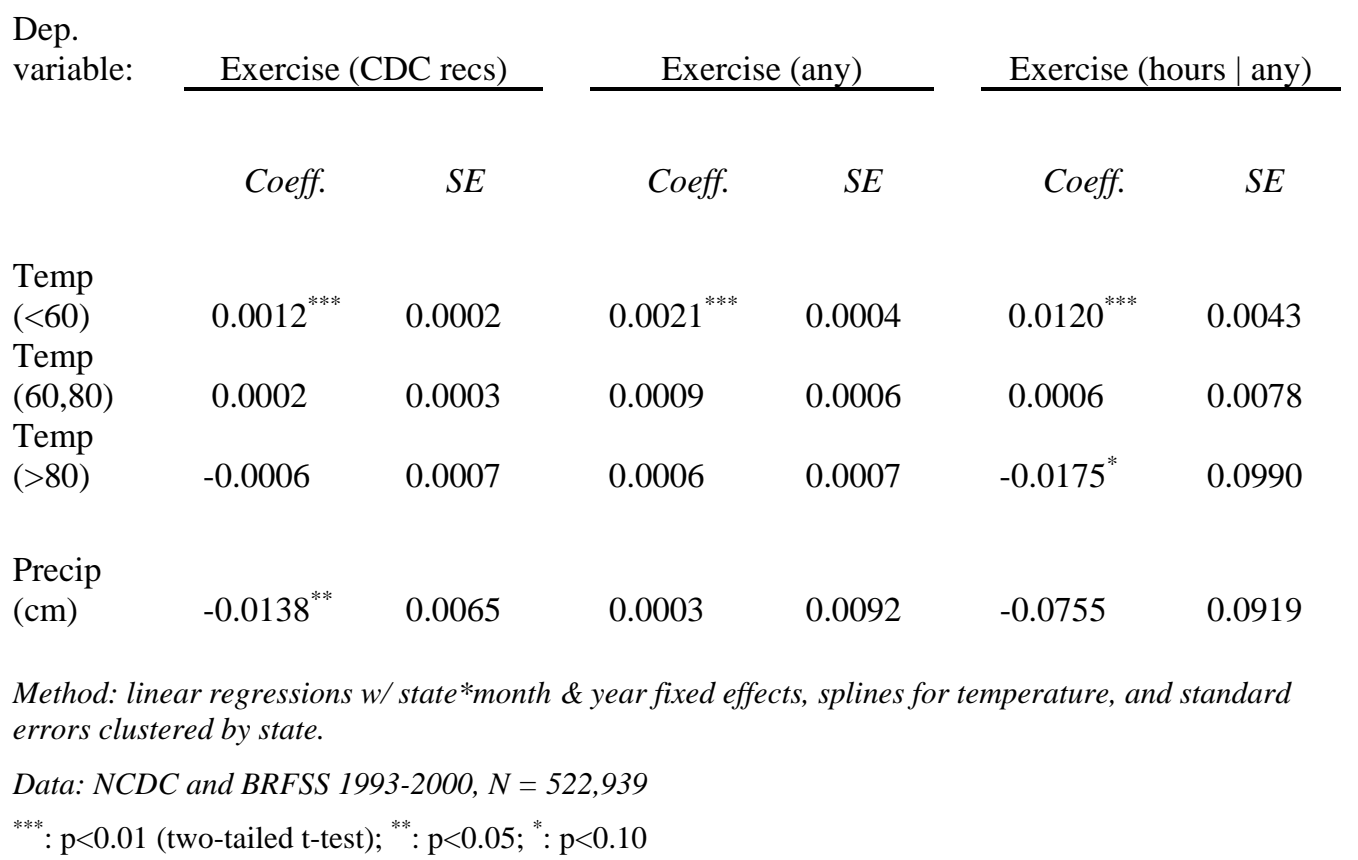

Table 4 shows analogous estimates broken down by education categories. These estimates provide some support for our hypothesis that the LTPA of lower SES groups is more sensitive to temperature shocks. Focusing on the lower temperature range ( $<60$ degrees), where the relationship with LTPA is most robust in the overall sample, one can see that people with a college degree have a smaller response to temperature shocks than less educated groups. This difference in coefficients is significant at $\mathrm{p}<0.05$, however, only for the second dependent variable (any exercise), when comparing the highest and lowest education groups. Relative to mean exercise participation (which is lower among lower SES groups, as already shown in Table 2), these coefficients imply effects 
2-3 times larger among those with a high school degree or less, as compared to those with a college degree.

The estimates by income category (Table 5) provide additional support for the hypothesis that lower SES groups are more sensitive to temperature shocks within the lower temperature ranges. In particular, people in households earning more than $\$ 50,000$ have a smaller response to temperature, within the lower temperature range, than people earning $\$ 15,000-\$ 25,000$ or $\$ 25,000-\$ 50,000$. The differences in coefficients for people over $\$ 50,000$ and people between $\$ 15,000-\$ 25,000$ are significant at $\mathrm{p}<0.05$ for the outcomes of meeting CDC guidelines and any exercise (but not for hours of exercise). Like the differential effects by education, these differential effects by income translate to effects 2-3 times larger among those from the lower SES groups, when the effects are compared to mean exercise participation.

On the other hand, the results for the lowest income group $(\$ 0-\$ 15,000)$ do not fit with these patterns, as the estimates for that group are not statistically different from zero. This may be partly due to the lower precision of these estimates (as evidenced by the smaller sample size and higher standard errors), and partly due to the fact that a low proportion of these people are employed (33\%, as compared to $63 \%$ of the overall sample) and as a result they may have quite different exercise habits and responses (e.g., they may have more flexibility to exercise during different times or days in response to weather shocks, which would help offset other factors - such as lack of gym memberships - associated with low SES). We have only a crude control variable for employment (a binary indicator), whereas a measure of hours worked per week would be needed to account for this issue more completely. 
Table 4: Effect of Weather on Exercise, By Education

Dep. variable:

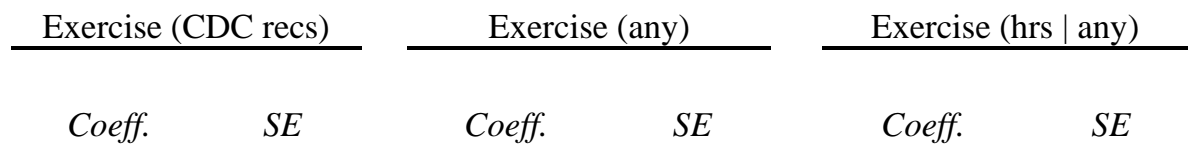

$\underline{\text { HS degree }}$

$\begin{array}{lllllll}\text { Temp } & & & & & \\ (<60) & 0.0012^{* * *} & 0.0003 & 0.0025^{* * *} & 0.0004 & 0.0094 & 0.0068 \\ \begin{array}{l}\text { Temp } \\ (60,80)\end{array} & 0.0003 & 0.0005 & 0.0007 & 0.0007 & 0.0049 & 0.0096 \\ \begin{array}{l}\text { Temp } \\ \begin{array}{l}(>80) \\ \text { Precip } \\ (\mathrm{cm})\end{array}\end{array} & -0.0002 & 0.0006 & 0.0004 & 0.0010 & -0.0117 & 0.0141 \\ & -0.0131 & 0.0081 & -0.0054 & 0.0123 & 0.0235 & 0.1603\end{array}$

$\underline{\text { Some college }}$

$\begin{array}{lllllll}\begin{array}{l}\text { Temp } \\ (<60)\end{array} & 0.0015^{* * *} & 0.0003 & 0.0022^{* * *} & 0.0006 & 0.0172^{* * *} & 0.0061 \\ \begin{array}{l}\text { Temp } \\ (60,80)\end{array} & -0.0006 & 0.0006 & 0.0007 & 0.0009 & -0.0054 & 0.0126 \\ \begin{array}{l}\text { Temp } \\ (>80)\end{array} & 0.0002 & 0.0007 & 0.0013^{*} & 0.0007 & -0.0124 & 0.0086 \\ \begin{array}{l}\text { Precip } \\ (\mathrm{cm})\end{array} & -0.0206^{*} & 0.0121 & 0.0035 & 0.0113 & -0.0673 & 0.1626\end{array}$

College degree

$\begin{array}{lcccccc}\begin{array}{l}\text { Temp } \\ (<60)\end{array} & 0.0008^{* *} & 0.0004 & 0.0013^{* * *} & 0.0004 & 0.0097^{* *} & 0.0047 \\ \begin{array}{l}\text { Temp } \\ (60,80)\end{array} & 0.0008 & 0.0006 & 0.0014^{* *} & 0.0007 & 0.0001 & 0.0086 \\ \begin{array}{l}\text { Temp } \\ (>80)\end{array} & -0.0023^{*} & 0.0013 & 0.0000 & 0.0009 & -0.0311^{*} & 0.0157 \\ \begin{array}{l}\text { Precip } \\ (\mathrm{cm})\end{array} & -0.0081 & 0.0107 & 0.0083 & 0.0130 & -0.2104^{* *} & 0.0982\end{array}$

Method: linear regressions w/ state*month \& year fixed effects, splines for temperature, and standard errors clustered by state.

Data: NCDC and BRFSS 1993-2000, $N=522,939$

*** $\mathrm{p}<0.01$ (two-tailed t-test); ${ }^{* *}: \mathrm{p}<0.05 ;{ }^{*}: \mathrm{p}<0.10$ 
Table 5: Effect of Weather on Exercise, By Income

Dep.

variable:

Exercise (CDC recs)

Coeff. SE

$\leq \$ 15,000$

Temp $(<60)$

Temp

$(60,80)$

Temp $(>80)$

Precip (cm)

$\$ 15,000-\$ 25,000$

Temp $(<60)$

$(60,80)$

Temp $(>80)$

Precip (cm)

$$
0.0006
$$

0.0001

0.0005

0.0007

$-0.0018$

0.0016

$-0.0108$

0.0106

0.0106

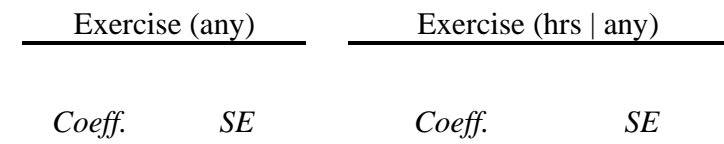

$\begin{array}{llll}0.0012 & 0.0007 & 0.0010 & 0.0121 \\ 0.0012 & 0.0010 & 0.0148 & 0.0133 \\ 0.0000 & 0.0012 & -0.0350 & 0.0330 \\ 0.0081 & 0.0183 & -0.1895 & 0.2785\end{array}$

$\begin{array}{llll}0.0081 & 0.0183 & -0.1895 & 0.2785\end{array}$

\section{$\underline{\$ 25,000-\$ 50,000}$}

$\begin{array}{lcccccc}\text { Temp }(<60) & 0.0013^{* * *} & 0.0004 & 0.0026^{* * *} & 0.0005 & 0.0099 & 0.0070 \\ \begin{array}{l}\text { Temp } \\ (60,80)\end{array} & 0.0007 & 0.0004 & 0.0023^{* *} & 0.0009 & 0.0091 & 0.0088 \\ \text { Temp (>80) } & -0.0008 & 0.0010 & 0.0003 & 0.0010 & -0.0175 & 0.0131 \\ \text { Precip (cm) } & -0.0004 & 0.0091 & 0.0106 & 0.0121 & 0.0378 & 0.1206\end{array}$

$>\$ 50,000$

$\begin{array}{lcccccr}\text { Temp }(<60) & 0.0009^{* *} & 0.0004 & 0.0014^{* * *} & 0.0005 & 0.0123^{* * *} & 0.0044 \\ \text { Temp } & & & & & & \\ (60,80) & 0.0000 & 0.0006 & 0.0007 & 0.0007 & -0.0071 & 0.0102 \\ \text { Temp }(>80) & -0.0014 & 0.0012 & 0.0007 & 0.0008 & -0.0257 & 0.0174 \\ \text { Precip (cm) } & -0.0249 & 0.0151 & 0.0086 & 0.0130 & -0.2543^{*} & 0.1303\end{array}$

Method: linear regressions $w /$ state*month \& year fixed effects, splines for temperature, and standard errors clustered by state. ${ }^{* * *}: \mathrm{p}<0.01$ (two-tailed t-test); ${ }^{* *}: \mathrm{p}<0.05 ;{ }^{*}: \mathrm{p}<0.10$

Data: NCDC, BRFSS 1993-00, $N=522,939$ 


\section{Outdoor versus Indoor Exercise}

The results in Table 6 show how outdoor exercise and indoor exercise respond to changes in temperature and precipitation. Again, the significant coefficients are for temperature in the low temperature range. In this range, as expected, temperature is positively associated with outdoor exercise and negatively associated with indoor exercise. The coefficient for outdoor exercise is much higher in absolute value, but relative to mean levels of participation (which are higher for outdoor exercise), the coefficients are similar in magnitude. Also, as one would expect, the sum of the coefficients for outdoor and indoor activities $(0.0032-0.0008=0.0024)$ corresponds closely to the coefficient for overall exercise (0.0021, in Table 3).

We next examine how outdoor and indoor exercise responds to weather differentially by SES (education in Table 8, income in Table 9). These results help illuminate why we find that the LTPA of lower SES groups is generally more sensitive to temperature shocks in the cold range. In part, the answer appears to be that outdoor activity declines more substantially as temperature drops, among lower SES groups (i.e., this coefficient is larger for lower SES groups, though the differences are not significant at $\mathrm{p}<0.05$ ). In addition, lower SES groups appear less likely to shift to indoor activities; in both tables, the coefficients for the two lower SES groups are closer to zero and not statistically significant, whereas the coefficients for the two higher SES groups are larger (more negative) and statistically significant (though, again, the differences are not significant at $\mathrm{p}<0.05$ ).

Roughly, half of the differential response of overall exercise participation by SES appears to be attributable to a larger response of outdoor activity, and half to a lower amount of shifting to indoor activity. For example, consider the comparison of people with income of $\$ 15,000-\$ 25,000$ as compared to those with greater than $\$ 50,000$. As shown in Table 5 , the lower SES group has a coefficient of 0.0029 for any exercise participation in the colder temperature range, as compared to 0.0014 for the higher SES group, equating to a differential response of 0.0015 . As shown in Table 8, the difference in outdoor activity coefficients is $0.0011(0.0039-0.0028)$ and the difference in indoor activity coefficients is 0.0010 $(-0.0002-(-.0012))$. Each of these differentials accounts for a bit more than half of the 0.0015 differential (note that the differentials for indoor and outdoor effects do not necessarily add exactly to the overall differential in exercise).

In interpreting the shifts from outdoor to indoor activities, it is important to keep in mind that we cannot definitively identify within-person substitution of one type of activity for another. Recall that the BRFSS are cross-sectional - we only have one observation per person. Therefore, within-person substitution is not the only possible explanation for the patterns we observe. Another possibility 
is that when the temperature is unusually cold, some people increase their indoor activity, whereas other people decrease their outdoor activity. In other words, the apparent "substitution" may be due to different responses across different people, rather than within-person responses.

\section{Table 6: Effect of Weather on Indoor and Outdoor Exercise, Full Sample}

\begin{tabular}{|c|c|c|c|c|}
\hline \multirow[t]{2}{*}{ Dep. variable: } & \multicolumn{2}{|c|}{$\begin{array}{l}\text { Outdoor Exer. } \\
\text { (past } 30 \text { days) }\end{array}$} & \multicolumn{2}{|c|}{$\begin{array}{l}\text { Indoor Exer. } \\
\text { (past } 30 \text { days) }\end{array}$} \\
\hline & Coeff. & $S E$ & Coeff. & $S E$ \\
\hline Temp $(<60)$ & $0.0032^{* * *}$ & 0.0004 & $-0.0008^{* * *}$ & 0.0003 \\
\hline Temp $(60,80)$ & 0.0007 & 0.0007 & -0.0002 & 0.0004 \\
\hline Temp (>80) & 0.0000 & 0.0008 & 0.0009 & 0.0007 \\
\hline Precip (cm) & -0.0044 & 0.0101 & -0.0059 & 0.0062 \\
\hline
\end{tabular}

Method: linear regressions w/ state*month \& year fixed effects, splines for temperature, and standard errors clustered by state.

Data: NCDC and BRFSS 1993-2000, $N=522,939$

${ }^{* * *}: \mathrm{p}<0.01$ (two-tailed t-test); ${ }^{* *}: \mathrm{p}<0.05$; $^{*}: \mathrm{p}<0.10$

\section{Sensitivity Checks}

The basic patterns of results - in which physical activity is significantly and negatively associated with temperature in cold temperature ranges, with this effect being higher among lower SES groups -- is robust to the following sensitivity checks (for which full results are available from authors on request). First, we reestimate the regressions using only the 24 states below the median in terms of land area, so as to restrict attention to cases where the state-level weather measures would reflect more precisely each individual's local weather conditions. In this sensitivity check it is especially notable that our estimated effect of precipitation is no larger than in the primary analysis; this suggests that the weak results for precipitation are probably not due to the fact that precipitation is measured with error at the state level because it is variable within states. 
Table 7: Effect of Weather on Indoor and Outdoor Exercise, By Education

\begin{tabular}{|c|c|c|c|c|}
\hline \multirow[t]{2}{*}{ Dep. variable: } & \multicolumn{2}{|c|}{$\begin{array}{l}\text { Outdoor Exer. } \\
\text { (past } 30 \text { days) }\end{array}$} & \multicolumn{2}{|c|}{$\begin{array}{l}\text { Indoor Exer. } \\
\text { (past } 30 \text { days) }\end{array}$} \\
\hline & Coeff. & $S E$ & Coeff. & $S E$ \\
\hline \multicolumn{5}{|c|}{$\underline{\text { HS degree or less }}$} \\
\hline Temp $(<60)$ & $0.0034^{* * *}$ & 0.0004 & -0.0004 & 0.0003 \\
\hline Temp $(60,80)$ & 0.0006 & 0.0007 & 0.0000 & 0.0005 \\
\hline Temp (>80) & -0.0005 & 0.0009 & $0.0016^{* *}$ & 0.0006 \\
\hline Precip (cm) & -0.0154 & 0.0146 & -0.0022 & 0.0087 \\
\hline \multicolumn{5}{|l|}{ Some college } \\
\hline Temp $(<60)$ & $0.0036^{* * *}$ & 0.0006 & $-0.0013^{* *}$ & 0.0006 \\
\hline Temp $(60,80)$ & 0.0003 & 0.0010 & -0.0003 & 0.0005 \\
\hline Temp (>80) & 0.0006 & 0.0009 & 0.0007 & 0.0010 \\
\hline Precip (cm) & 0.0020 & 0.0133 & -0.0146 & 0.0107 \\
\hline \multicolumn{5}{|l|}{$\underline{\text { College degree }}$} \\
\hline Temp $(<60)$ & $0.0027^{* * *}$ & 0.0005 & $-0.0012^{* * *}$ & 0.0004 \\
\hline Temp $(60,80)$ & $0.0012^{*}$ & 0.0007 & -0.0002 & 0.0007 \\
\hline Temp (>80) & 0.0001 & 0.0009 & 0.0001 & 0.0015 \\
\hline Precip (cm) & 0.0084 & 0.0132 & -0.0027 & 0.0096 \\
\hline \multicolumn{5}{|c|}{$\begin{array}{l}\text { Method: lin. regs. w/ state*month \& year FE's, splines for temperature, SE's clustered by state. } \\
\text { Data: NCDC and BRFSS 1993-2000, } N=522,939 \\
{ }^{* * *}: \mathrm{p}<0.01 \text { (two-tailed t-test); }{ }^{* *}: \mathrm{p}<0.05 ;{ }^{*}: \mathrm{p}<0.10\end{array}$} \\
\hline
\end{tabular}


Table 8: Effect of Weather on Indoor and Outdoor Exercise, By Income

Dep. variable:

\begin{tabular}{l}
$\begin{array}{l}\text { Outdoor Exer. } \\
\text { (past 30 days) }\end{array}$ \\
\hline Coeff. $\quad S E$
\end{tabular}

$\leq \$ 15,000$

Temp $(<60)$

Temp $(60,80)$

Temp (>80)

Precip (cm)

$\$ 15,000-\$ 25,000$

Temp $(<60)$
Temp $(60,80)$
Temp $(>80)$
Precip (cm)

$\$ 25,000-\$ 50,000$

Temp $(<60)$

Temp $(60,80)$

Temp (>80)

Precip (cm)

$\geq \$ 50,000$

$\begin{array}{lllll}\text { Temp }(<60) & 0.0028^{* * *} & 0.0006 & -0.0012^{* *} & 0.0005 \\ \text { Temp }(60,80) & 0.0004 & 0.0007 & -0.0004 & 0.0005 \\ \text { Temp (>80) } & 0.0009 & 0.0013 & 0.0008 & 0.0012 \\ & & & & \\ \text { Precip (cm) } & 0.0023 & 0.0140 & -0.0069 & 0.0109\end{array}$

Indoor Exer. (past 30 days)

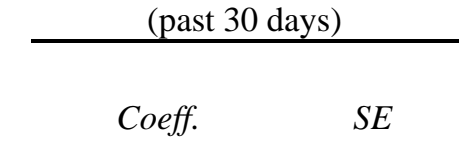

$\begin{array}{cccc}0.0025^{* * *} & 0.0007 & -0.0008^{* *} & 0.0004 \\ 0.0011 & 0.0009 & 0.0000 & 0.0008 \\ -0.0011 & 0.0014 & 0.0014 & 0.0010 \\ 0.0039 & 0.0200 & 0.0039 & 0.0160\end{array}$

$\begin{array}{llcl}0.0039^{* * *} & 0.0007 & -0.0002 & 0.0005 \\ -0.0013 & 0.0011 & -0.0011^{*} & 0.0007 \\ -0.0007 & 0.0014 & 0.0003 & 0.0010 \\ -0.0212 & 0.0186 & -0.0055 & 0.0102\end{array}$

$\begin{array}{llll}0.0037^{* * *} & 0.0004 & -0.0010^{* *} & 0.0005 \\ 0.0024^{* *} & 0.0009 & -0.0001 & 0.0007 \\ -0.0008 & 0.0010 & 0.0007 & 0.0010 \\ -0.0004 & 0.0129 & -0.0019 & 0.0080\end{array}$

Method: lin. regs. w/ state*month \& year FE's, splines for temperature, SE's clustered by state.

Data: NCDC and BRFSS 1993-2000, $N=522,939$

***: $\mathrm{p}<0.01$ (two-tailed t-test); ${ }^{* *}: \mathrm{p}<0.05 ;{ }^{*}: \mathrm{p}<0.10$ 
Second, we re-estimate the regressions without individual covariates (age, gender, race/ethnicity, marital status, employment status), as these covariates should not be correlated with weather shocks and therefore should not affect the results substantially. Third, we use logistic instead of linear specifications for the binary dependent variables (meeting CDC guidelines for exercise and any exercise participation). Fourth, we redefine the cold temperature range to two alternatives: lower than 40 degrees, or lower than 50 degrees. In these two alternative analyses, the association between temperature and LTPA remains significant and negative in the cold range, and the association also becomes significant and negative in the middle temperature range in the former case (40 degrees as the upper limit of the cold range). Fifth, instead of using a linear spline for temperature, we use a linear and squared term, and we find as expected that the linear term is positive and significant and the squared term is negative significant (implying the bowed relationship shown in Figure 1).

To examine the robustness of our results for outdoor versus indoor activities, we restrict the definitions of outdoor and indoor to the more clear-cut cases (using only activities that are "clearly" indoor or outdoor, as defined in the Appendix). We also run an alternative version of the analysis of the outdoor or indoor activities, in which we conservatively exclude activities that cannot be unequivocally assigned to "mostly outdoor “ or "mostly indoor" (badminton, basketball, calisthenics, swimming). In these robustness checks the main pattern of results for outdoor versus indoor activities remains the same as in Tables 6-8.

\section{Additional Sub-group Analyses}

In addition to our analyses by SES group, we also conduct stratified analyses by gender, employment status, and warmer versus colder states (24 states with the warmest average temperature as compared to the 24 with the coldest). For females versus males, we find that the estimated effects of weather on LTPA are almost identical. By contrast, the results by employment status indicate that LTPA as measured by meeting CDC guidelines is more sensitive to cold weather and precipitation for those who are not employed. This pattern does not hold for the other outcome measures, however, with the exception of the response of hours per week of exercise to cold weather. On balance the results by employment status suggest that any increased flexibility in schedule for those who are not employed is not sufficient to offset factors shared with lower SES groups (e.g. lack of access to indoor exercise facilities) that make their LTPA more sensitive to weather shocks.

The comparison of warmer versus colder states yields two interesting differences. First, in the cold temperature range, temperature has a significant positive relationship with indoor activities in the colder states (coefficient of 
0.0012 , significant at $\mathrm{p}<0.01$ ) but not in the warmer states. This is consistent with the idea that people in colder states are more prepared to shift to indoor activities during colder weather, which may be because they have more indoor facilities or because they are simply more accustomed to switching to indoor activities as needed. Second, in the warmer temperature range (above 80 degrees), temperature has a significant negative relationship with outdoor activity in the colder states (coefficient of -0.0024 , significant at $\mathrm{p}<0.10$ ) but not the warmer states. This implies that the physical activity of people in northern states is more sensitive to unusually hot weather, perhaps because they are less accustomed in general to hot weather. It is also worth noting that the analysis by warmer versus colder states indicates that the effect of cold temperature on overall LTPA is present in both types of states (i.e. the effect is significant and similar in magnitude for meeting CDC guidelines and exercising at all in both types of states).

\section{Conclusion}

This is the first study, to our knowledge, to estimate the effects of environmental factors on exercise behavior using essentially random variation in those conditions. We find evidence for modest effects of temperature on LTPA for all SES groups, with the larger effects generally for people with lower educational attainment or income (though, as noted earlier, this pattern is not consistent across every outcome variable and SES category). In lower temperature ranges, increases in temperature have a positive effect on the probability that people engage in LTPA, or equivalently, decreases in temperature have a negative effect on LTPA. Roughly, the stronger response to colder temperatures by lower SES groups appears to be due in half to larger reductions in outdoor activity and in half to smaller increases in indoor activity.

The differential responses of LTPA to weather shocks by SES could be due to multiple factors, including differences in access to exercise spaces and equipment, differences in schedule and transportation constraints, and differences in preferences about various activities. Our data do not allow us to examine these factors directly, but the fact that lower SES groups are less likely to shift to indoor activities suggests that lower availability of indoor facilities may be an important factor on the margin.

In general, our results are consistent with the broad idea that environmental factors are important determinants of health behaviors, and that such factors are also important factors in socioeconomic disparities for these behaviors. The fact that exercise is inversely related to SES is well known; the new finding here is that the behavior of lower SES people is more elastic with respect to weather on the margin. This higher elasticity may be specific to 
weather, reflecting lower availability of indoor substitutes. In this case, interventions and policies that increase options for indoor LTPA, particularly among lower SES groups, are likely to be effective in increasing overall LTPA. Furthermore, to the extent that the higher elasticity of behavior for lower SES groups reflects a more general sensitivity to external factors, this highlights the promise of interventions that address such factors more broadly. A priority for future research is to investigate which specific aspects of socioeconomic status explain differential responses to environmental conditions. 


\section{References}

Aarts H, Paulussen T, Schaalma H. Physical exercise habit: on the conceptualization and formation of habitual health behaviours. Health Education Research 1997 Sep; 12(3):363-74.

Arroll B, Beaglehole R. Does physical activity lower blood pressure? A critical review of the clinical trials. Journal of Clinical Epidemiology 1992; 45:439447.

Ball K, Salmon J, Giles-Corti B, Crawford D. How can socio-economic differences in physical activity among women be explained? A qualitative study. Women \& Health. 2006; 43 (1): 93-113.

Berlin JA, Colditz GA. A meta-analysis of physical activity in the prevention of coronary heart disease. American Journal of Epidemiology 1990;132:612628.

Burton NW, Turrell G, Olderburg B. Participation in recreational physical activity: why do socioeconomic groups differ? Health Education and Behavior 2003 Apr; 30(2):225-44.

Cawley, J. An economic framework for understanding physical activity and eating behaviors. American Journal of Preventive Medicine 2004; 27(3S): 117-125.

Centers for Disease Control (CDC). Exercise guidelines retrieved from http://www.cdc.gov/nccdphp/dnpa/physical/recommendations/index.htm on May 20, 2006.

Centers for Disease Control (CDC). Prevalence of Regular Physical Activity Among Adults --- United States, 2001 and 2005. MMWR Weekly, November 23, 2007; 56(46):1209-1212.

Cutler, D., Lleras-Muney, A. Education and Health: Evaluating Theories and Evidence. NBER Working Paper \#12352.

Davis TC, Arnold C, Berkel HJ, Nandy I, Jackson RH, Glass J. Knowledge and attitude on screening mammography among low-literate, low-income women. Cancer. 1996 Nov; 78(9):1912-20. 
Duncan JJ, Gordon NF, Scott CB. Women walking for health and fitness: how much is enough? Journal of the American Medical Association 1991;266:3295-3299.

Gerhardsson M, Steineck G, Hagman U, Rieger Å, Norell SE. Physical activity and colon cancer: a case-referent study in Stockholm. International Journal of Cancer 1990;46:985-989.

He, Xiaoxing Z, Baker D. Differences in Leisure-time, Household, and Workrelated Physical Activity by Race, Ethnicity, and Education. Journal of General Internal Medicine 2005; 20: 259-265.

Heien D., Durham C.. A Test of the Habit Formation Hypothesis Using Household Data. The Review of Economics and Statistics 1991 May; 73(2):189-199.

Hillsdon M, Panter J, Foster C, Jones A. Equitable access to exercise facilities.

American Journal of Preventive Medicine 2007 Jun; 32(6):506-8.

Humphreys B., Ruseski J. Economic determinants of participation in physical activity and sport. Working Paper No. 06-13, 2006, International Association of Sports Economists.

Humphreys B., Ruseski J. Participation in physical activity and government spending on parks and recreation. Contemporary Economic Policy 2007; 25(4): 538-552.

Lee CJ, Lawler GS, Panemangalore M, Street D. Nutritional status of middleaged and elderly females in Kentucky in two seasons: Part 1. Body weight and related factors. Journal of the American College of Nutrition. 1987 Jun; 6(3):209-15.

Matthews CE, Freedson PS, Hebert JR, Stanek EJ 3rd, Merriam PA, Rosal MC,

Ebbeling CB, Ockene IS. Seasonal variation in household, occupational, and leisure time physical activity: longitudinal analyses from the seasonal variation of blood cholesterol study. American Journal of Epidemiology. 2001 Jan 15;153(2):172-83.

Mensah G, Mokdad A, Ford E, Greenlund K, Croft J . State of Disparities in Cardiovascular Health in the United States. Circulation. 2005;111:12331241. 
Philipson, T., Posner, R. The long-run growth in obesity as a function of technological change. NBER Working Paper No. 7423, 1999.

Powell LM, Slater S, Chaloupka FJ, Harper D. Availability of physical activityrelated facilities and neighborhood demographic and socioeconomic characteristics: a national study. American Journal of Public Health. 2006 Sep; 96(9):1676-80

Ruhm, C. Are recessions good for your health? The Quarterly Journal of Economics 2000; 617-650.

Ruhm, C. Healthy living in hard times. Journal of Health Economics 2005; 24: 341-363.

Pivarnik JM, Reeves MJ, Rafferty AP. Seasonal variation in adult leisure-time physical activity. Medical Science in Sports and Exercise. 2003 Jun;35(6):1004-8.

Srinivasan, Shobha PhD, Liam R. O'Fallon, MA and Allen Dearry, PhD. Reviewing the Evidence: Creating Healthy Communities, Healthy Homes, Healthy People: Initiating a Research Agenda on the Built Environment and Public Health. American Journal of Public Health 2003, Vol 93, No. 9: 1446-1450.

US Department of Health and Human Services. Physical activity and health: report of the Surgeon General. Atlanta, Georgia: US Department of Health and Human Services, CDC, National Center for Chronic Disease Prevention and Health Promotion, 1996.

Visscher TL, Seidell JC. Time trends (1993-1997) and seasonal variation in body mass index and waist circumference in the Netherlands. International Journal of Obesity and Related Metabolic Disorders 2004 Oct;28(10):130916. 


\section{Appendix A: Participation and outdoor/indoor classifications, by type of LTPA*}

\begin{tabular}{|c|c|c|c|c|c|c|c|}
\hline Type of LTPA & Total & $\begin{array}{l}\text { Primary } \\
\text { activity }\end{array}$ & $\begin{array}{l}\text { Secondary } \\
\text { activity }\end{array}$ & $\begin{array}{l}\text { Times per } \\
\text { week** }^{* *}\end{array}$ & $\begin{array}{l}\text { Minutes } \\
\text { per time }\end{array}$ & $M E T^{* * *}$ & $\begin{array}{l}\text { Outdoor/ } \\
\text { Indoor }\end{array}$ \\
\hline Walking & $37.57 \%$ & $32.29 \%$ & $5.28 \%$ & 3.5 & 46.2 & 3.5 & Out (mostly) \\
\hline Gardening & $7.32 \%$ & $4.62 \%$ & $2.69 \%$ & 2.7 & 120.4 & 5 & Out (clearly) \\
\hline Weightlifting & $6.40 \%$ & $3.32 \%$ & $3.08 \%$ & 3.3 & 61 & 6 & In (clearly) \\
\hline Running & $5.96 \%$ & $4.64 \%$ & $1.32 \%$ & 3.1 & 42.6 & 8 & Out (mostly) \\
\hline Other & $4.88 \%$ & $2.60 \%$ & $2.27 \%$ & 3.1 & 88.4 & & \\
\hline $\begin{array}{l}\text { Bicycling for } \\
\text { pleasure }\end{array}$ & $4.81 \%$ & $2.66 \%$ & $2.16 \%$ & 2.8 & 62.3 & 8 & Out (clearly) \\
\hline Aerobics class & $4.44 \%$ & $3.17 \%$ & $1.27 \%$ & 3 & 51.5 & 6.5 & In (clearly) \\
\hline Golf & $4.15 \%$ & $2.52 \%$ & $1.62 \%$ & 1.5 & 205.8 & 4.5 & Out (clearly) \\
\hline Basketball & $2.96 \%$ & $1.88 \%$ & $1.08 \%$ & 2.2 & 102.6 & 8 & Out (mostly) \\
\hline Home exercise & $2.79 \%$ & $1.71 \%$ & $1.07 \%$ & 3.9 & 36.9 & 3 & In (clearly) \\
\hline Swimming laps & $2.49 \%$ & $1.13 \%$ & $1.37 \%$ & 2.6 & 55.5 & 7 & In (mostly) \\
\hline Calisthenics & $1.78 \%$ & $0.94 \%$ & $0.84 \%$ & 3.9 & 36.3 & 8 & In (mostly) \\
\hline $\begin{array}{l}\text { Jogging } \\
\text { Health }\end{array}$ & $1.74 \%$ & $1.25 \%$ & $0.49 \%$ & 3 & 39.6 & 7 & Out (mostly) \\
\hline $\begin{array}{l}\text { exercise } \\
\text { Bicycling }\end{array}$ & $1.62 \%$ & $1.15 \%$ & $0.48 \%$ & 3.1 & 65.5 & 5.5 & In (clearly) \\
\hline machine exercise & $1.38 \%$ & $0.76 \%$ & $0.62 \%$ & 3.5 & 28.5 & 7 & In (clearly) \\
\hline Softball & $1.24 \%$ & $0.71 \%$ & $0.53 \%$ & 2 & 109.8 & 5 & Out (clearly) \\
\hline Tennis & $1.15 \%$ & $0.64 \%$ & $0.52 \%$ & 2 & 96.1 & 7 & Out (mostly) \\
\hline $\begin{array}{l}\text { Dancing- } \\
\text { aerobics/ballet }\end{array}$ & $0.89 \%$ & $0.45 \%$ & $0.45 \%$ & 2.1 & 113.5 & 5 & In (clearly) \\
\hline Bowling & $0.79 \%$ & $0.38 \%$ & $0.41 \%$ & 1.5 & 139.5 & 3 & In (clearly) \\
\hline $\begin{array}{l}\text { Hiking cross } \\
\text { country }\end{array}$ & $0.79 \%$ & $0.48 \%$ & $0.31 \%$ & 1.5 & 157.7 & 6 & Out (clearly) \\
\hline Volleyball & $0.66 \%$ & $0.34 \%$ & $0.31 \%$ & 1.6 & 108.7 & 4 & In (mostly) \\
\hline Soccer & $0.66 \%$ & $0.46 \%$ & $0.20 \%$ & 1.9 & 92.5 & 7 & Out (mostly) \\
\hline $\begin{array}{l}\text { Skating - ice or } \\
\text { roller }\end{array}$ & $0.60 \%$ & $0.33 \%$ & $0.27 \%$ & 2 & 86.3 & 7 & In (mostly) \\
\hline Mowing lawn & $0.58 \%$ & $0.26 \%$ & $0.33 \%$ & 1.4 & 117.3 & 5.5 & Out (clearly) \\
\hline Stair climbing & $0.50 \%$ & $0.25 \%$ & $0.25 \%$ & 3.8 & 31.1 & 8 & Out (mostly) \\
\hline Snow skiing & $0.45 \%$ & $0.24 \%$ & $0.21 \%$ & 1.7 & 216 & 7 & Out (clearly) \\
\hline Racquetball & $0.44 \%$ & $0.26 \%$ & $0.19 \%$ & 1.9 & 79.1 & 7 & In (clearly) \\
\hline $\begin{array}{l}\text { Fishing from } \\
\text { riverbank or boat }\end{array}$ & $0.36 \%$ & $0.16 \%$ & $0.21 \%$ & 1.7 & 258.4 & 3 & Out (clearly) \\
\hline Horseback riding & $0.34 \%$ & $0.19 \%$ & $0.16 \%$ & 2.8 & 119.5 & 4 & Out (mostly) \\
\hline Judo/karate & $0.34 \%$ & $0.23 \%$ & $0.11 \%$ & 3.2 & 85.9 & 10 & In (clearly) \\
\hline $\begin{array}{l}\text { Hunting large } \\
\text { game - deer, elk }\end{array}$ & $0.29 \%$ & $0.19 \%$ & $0.10 \%$ & 2.5 & 264.3 & 6 & Out (clearly) \\
\hline
\end{tabular}




\begin{tabular}{|c|c|c|c|c|c|c|c|}
\hline $\begin{array}{l}\text { Snow shoveling } \\
\text { by hand }\end{array}$ & $0.20 \%$ & $0.10 \%$ & $0.10 \%$ & 1.5 & 65.1 & 6 & Out (clearly) \\
\hline Touch football & $0.19 \%$ & $0.10 \%$ & $0.09 \%$ & 2 & 114 & 8 & Out (clearly) \\
\hline $\begin{array}{l}\text { Rowing machine } \\
\text { exercise }\end{array}$ & $0.17 \%$ & $0.08 \%$ & $0.09 \%$ & 3.4 & 29.4 & 7 & In (clearly) \\
\hline Waterskiing & $0.17 \%$ & $0.08 \%$ & $0.09 \%$ & 1.7 & 100.1 & 6 & Out (clearly) \\
\hline Carpentry & $0.13 \%$ & $0.07 \%$ & $0.06 \%$ & 3.2 & 246 & 3 & In (mostly) \\
\hline Raking lawn & $0.11 \%$ & $0.06 \%$ & $0.05 \%$ & 1.8 & 124.5 & 4 & Out (clearly) \\
\hline Boating & $0.11 \%$ & $0.05 \%$ & $0.06 \%$ & 1.9 & 185.2 & 3.5 & Out (clearly) \\
\hline Boxing & $0.09 \%$ & $0.05 \%$ & $0.04 \%$ & 3.2 & 79.1 & 9 & In (clearly) \\
\hline Surfing & $0.09 \%$ & $0.06 \%$ & $0.03 \%$ & 2.8 & 143.9 & 3 & Out (clearly) \\
\hline $\begin{array}{l}\text { Canoeing, rowing } \\
\text { in competition }\end{array}$ & $0.08 \%$ & $0.03 \%$ & $0.04 \%$ & 1.6 & 171.4 & 12 & Out (clearly) \\
\hline $\begin{array}{l}\text { Mountain } \\
\text { climbing } \\
\text { Painting/papering }\end{array}$ & $0.06 \%$ & $0.03 \%$ & $0.03 \%$ & 1.9 & 165.9 & 8 & Out (clearly) \\
\hline house & $0.06 \%$ & $0.03 \%$ & $0.03 \%$ & 2.9 & 264.2 & 3 & In (mostly) \\
\hline Handball & $0.05 \%$ & $0.03 \%$ & $0.02 \%$ & 2 & 92.9 & 12 & In (clearly) \\
\hline Scuba diving & $0.04 \%$ & $0.02 \%$ & $0.02 \%$ & 1.6 & 112 & 7 & Out (clearly) \\
\hline Badminton & $0.03 \%$ & $0.02 \%$ & $0.02 \%$ & 2.1 & 81 & 4.5 & Out (mostly) \\
\hline Rope skipping & $0.03 \%$ & $0.01 \%$ & $0.02 \%$ & 3.7 & 32.6 & 10 & In (mostly) \\
\hline Table tennis & $0.03 \%$ & $0.01 \%$ & $0.01 \%$ & 2.2 & 93.1 & 4 & In (clearly) \\
\hline Backpacking & $0.02 \%$ & $0.01 \%$ & $0.01 \%$ & 1.6 & 212.2 & 7 & Out (clearly) \\
\hline Snow shoeing & $0.02 \%$ & $0.01 \%$ & $0.01 \%$ & 1.4 & 109.9 & 8 & Out (clearly) \\
\hline $\begin{array}{l}\text { Sledding, } \\
\text { tobogganing }\end{array}$ & $0.02 \%$ & $0.01 \%$ & $0.01 \%$ & 1.3 & 127.3 & 7 & Out (clearly) \\
\hline Squash & $0.02 \%$ & $0.01 \%$ & $0.01 \%$ & 2 & 68.2 & 12 & In (clearly) \\
\hline Paddleball & $0.01 \%$ & $0.01 \%$ & $0.01 \%$ & 1.9 & 106.7 & 6 & Out (mostly) \\
\hline Snorkeling & $0.01 \%$ & $0.00 \%$ & $0.01 \%$ & 1.5 & 95.8 & 5 & Out (clearly) \\
\hline Snow blowing & $0.01 \%$ & $0.01 \%$ & $0.00 \%$ & 1.7 & 112.6 & 4.5 & Out (clearly) \\
\hline $\begin{array}{l}\text { Stream fishing in } \\
\text { waders }\end{array}$ & $0.01 \%$ & $0.01 \%$ & $0.00 \%$ & 2.2 & 160.3 & 6 & Out (clearly) \\
\hline
\end{tabular}

